\title{
Relation between College Students' Conservatism and Negative Stereotypes about Social Groups
}

\author{
Sylvia Beyer (iD \\ Department of Psychology, University of Wisconsin-Parkside, Kenosha, WI 53141, USA; beyer@uwp.edu
}

Received: 22 October 2020; Accepted: 1 December 2020; Published: 4 December 2020

check for updates

\begin{abstract}
This study examined the interrelations among political attitudes and negative stereotypes in U.S. undergraduates. Participants answered questions measuring conservatism, social dominance orientation, Global Belief in a Just World, and religiosity. This research employed two measures of stereotypes: modern sexism and feelings about 15 social groups. It was hypothesized that conservatives would show more evidence of negative stereotypes than liberals would. The study revealed that indeed conservatives show stronger evidence of negative stereotypes, but that liberals also harbor some biases. Importantly, the social groups against whom conservatives and liberals are stereotyped differed greatly. Conservatives showed considerably more negative stereotypes against racial and religious minorities, and particularly against those who do not identify with the cis-gender, heterosexual norm. Thus, the targets of conservatives' stereotypes were groups that have traditionally been subject to discrimination. Liberals held stronger stereotypes against groups that are more politically powerful, such as Caucasians and Christians.
\end{abstract}

Keywords: stereotypes; prejudice; political attitudes; conservatism

\section{Relation between College Students' Conservatism and Negative Stereotypes about Social Groups}

The USA is currently experiencing strong political polarization with increasing tensions among social groups from different racial or ethnic backgrounds, political affiliations, religions, or sexual orientations and identities (e.g., Crandall et al. 2018). Furthermore, "fake news" has become a buzzword amid justified concerns about the weaponizing of social media by governments and political groups. This provides fertile ground for social psychological research on the relation between political attitudes and negative stereotypes in U.S. undergraduates. This paper examines the relations among political attitudes, personality variables, and negative stereotypes.

\section{The Relation between Political Attitudes and Negative Stereotypes about Social Groups}

Much social psychological research immediately after World War II focused on the dangers of right-wing authoritarianism's relation to cognitive biases and prejudice (e.g., Adorno et al. 1950). After the cognitive revolution in psychology, this area of research lay dormant for several decades. During this millennium, there has been a resurgence of interest in psychology in the relation between political attitudes and prejudice. Recent research in the U.S. has found that conservative compared to liberal political views are associated with greater prejudice, a phenomenon referred to as "prejudice gap" by Chambers et al. (2013). For example, social conservatism, i.e., holding conservative views of social issues such as abortion or lesbian, gay, bisexual, transgender, or queer (LGBTQ) rights, correlates with higher levels of racial prejudice and homophobia (Hodson and Dhont 2015). According to Jost et al. (2018, p. 69) "conservatives engage in more heuristic, automatic, stereotypical [ . . ] thinking, whereas liberals engage in more systematic, controlled, effortful [ ... ] thinking." Conservatives' cognitive shortcuts in information processing could then lead to biases towards social groups. 
Related to conservatism is social dominance orientation (SDO), which is conceptualized as a "general attitudinal orientation toward intergroup relations, reflecting whether one generally prefers such relations to be equal, versus hierarchical" (Pratto et al. 1994, p. 742). SDO predicts prejudice towards outgroups as those high in SDO value power and dominance and who see the social world as replete with competition (Hodson and Dhont 2015). Conservatism also correlates with Global Belief in a Just World (GBJW; Dittmar and Dickinson 1993), the notion that good things happen to good people and bad things to bad people. In a nutshell, GBJW serves to justify the status quo; for example, poor people are perceived as lazy and hence deserving of their lot, and shootings of people of color are deemed justified when people of color are perceived to be innately aggressive. In summary, researchers have found evidence that politically conservative individuals and those high in SDO and GBJW tend to hold unempathetic, domineering, and negative stereotypical attitudes towards racial and sexual minorities.

However, more recently, the view that political conservatives, more so than liberals, display information processing biases and negative stereotypes against social groups, has been challenged. A meta-analysis by Ditto et al. (2018) found that liberals and conservatives showed similar information processing biases (but see the critique of this study by Baron and Jost 2019). Similarly, according to Brandt et al. (2014) and Chambers et al. (2013), conservatives and liberals show similarly negative stereotypes, which tend to be directed against those with opposing viewpoints. For example, Crawford and Brandt (2019) demonstrated that in the US liberals were also biased, viz., against conservatives. Furthermore, conservatives and liberals alike supported discrimination against individuals who violated their values (Wetherell et al. 2013). Thus, this strand of research suggests that individuals with strong political convictions, regardless of their specific political leanings, are biased against those with opposing viewpoints, i.e., outgroups. Brandt et al. (2014) labeled this the "ideological-conflict hypothesis." This in-group bias would also be predicted by social identity theory (e.g., Tajfel 1982). Similarly, the similarity-liking principle (Byrne 1971) also posits that we like those who hold similar values to our own and dislike those who hold values that do not coincide with our own.

Thus, according to one research strand, political conservatism more so than liberalism brings with it an inclination to view outgroups negatively. An opposing strand of research claims that negatively viewing outgroups is not a hallmark of conservatism, but rather a phenomenon to which liberals fall prey as well, since it represents the general phenomenon of in-group bias. In a nutshell, the question is whether ingroup bias is equally prevalent in conservatives and liberals or whether it mostly falls within the province of conservatism.

Much of the previous research only examined political groups' stereotypes against a few groups (for an exception see Chambers et al. 2013), which can easily lead to confounding stereotypes against a social group (e.g., a racial minority) with antipathy towards that group's supposed political ideology (e.g., African Americans' liberalism) (see Brandt et al. 2014). The present research was designed to address whether conservatives and liberals show similar levels of negative stereotypes, only differing in the social groups against which they are biased, viz., those most at odds with their beliefs, by examining stereotypes against 15 different social groups. The goal was to include a variety of social groups that align with either conservative or liberal ideologies. Furthermore, this study assessed whether SDO and GBJW also correlate with stereotypes about certain social groups. Religiosity may also be tied to negative feelings about certain social groups (Hodson and Dhont 2015). To further our understanding of the relations among political attitudes, religiosity, and stereotypes of social groups, this study also assessed college students' religiosity and religious affiliations.

Recent research on the relation between political attitudes and the Big Five personality factors has found that conservative individuals tend to score lower on openness to new experiences and higher on conscientiousness, whereas liberals tend to be higher on openness and lower on conscientiousness (Carney et al. 2008; Crawford and Brandt 2019; Hirsh et al. 2010; Jost et al. 2007). Do these personality factors also correlate with holding negative stereotypes of social groups? One Big Five personality factor has recently come under scrutiny for its possible role in stereotyping. Research suggests that those 
who are low in agreeableness tend to hold generally prejudiced views against several social groups (Brandt and Crawford 2019; Crawford and Brandt 2019; Sibley and Duckitt 2008). A meta-analysis has also linked low openness to new experiences to prejudice (Sibley and Duckitt 2008).

The connection between political attitudes, negative stereotypes about social groups, and personality is far from settled. For this reason, this study endeavored to assess the relation between political attitudes, the Big Five, and stereotyping. It was hypothesized that conservative individuals would display more negative stereotypes than liberal individuals, especially towards disadvantaged social groups. Furthermore, the study also predicts that individuals high in SDO, GBJW, and religiosity show more negative stereotypes. The study also endeavored to examine the relation between Big Five factors and stereotypes, predicting that those lower in agreeableness would hold more negative stereotypes about certain social groups.

\section{Method}

\subsection{Participants}

A total of 115 introductory psychology students from a small, public university in the Midwest of the US participated during the fall 2017 and spring 2018 semesters. The students' average age was 19.9 (range of 18 to 49 ) years. Gender identification was reported by 114 students ( 67 females, 46 males, 1 other) and race identification by 115 students (64 Caucasian, 17 Multi-racial, 16 African American, 9 Hispanic ${ }^{1}$, 6 Asian, 2 Native Americans, and 1 other). Students also reported their religious affiliations (73 Christian, 21 Atheist or Agnostic, 10 non-religious, 7 other, and 3 Muslim). Participants received course credit for their participation.

\subsection{Materials}

Measures of conservatism, SDO, GBJW, religiosity, and personality. The Social and Economic Conservatism Scale (SECS) contains 12 items (Everett 2013). It allows participants to rank their feelings on social issues on a scale from zero (greater negativity) to 100 (greater positivity). The SECS is subdivided into two subscales: social and economic conservatism. Social conservatism items include attitudes toward abortion, military and national security, religion, traditional marriage, traditional values, the family unit, and patriotism. Items measuring economic conservatism relate to attitudes toward limited government, welfare benefits, gun ownership, fiscal responsibility, and business. Reliabilities of the SECS range from 0.70 to 0.87 (Everett 2013).

The scale measuring social dominance orientation (SDO; Ho et al. 2015) is also split into two subscales; dominance and anti-egalitarianism. Each subscale consists of eight statements. For this study, participants responded on a scale from zero (strongly disagree) to seven (strongly agree). The dominance subscale includes statements such as "some groups of people must be kept in their place" and "an ideal society requires some groups to be on top and others to be on the bottom" (Ho et al. 2015). The anti-egalitarianism subscale includes statements such as "we should not push for group equality" and "it is unjust to try to make groups equal" (Ho et al. 2015). Reliabilities for the dominance portion of the SDO scale range from 0.59 to 0.80 , and for the anti-egalitarianism portion from 0.68 to 0.86 (Ho et al. 2015). Because the results for the two sub-scales were almost identical, the two sub-scales were averaged into an overall SDO score.

A Likert scale was used to assess "self-identified conservatism", ranging from 1 (very liberal) to 7 (very conservative). Religiosity was assessed on a Likert scale from 1 (not religious) to 7 (very religious). Both of these items were at the very end of the survey, embedded among the demographic questions.

1 Although Hispanic is officially considered an ethnicity rather than a race, so many of our participants spontaneously typed in "Hispanic" under the racial category "Other" that I decided to honor this self-categorization. 
Global Belief in a Just World (GBJW; Lipkus 1991) is a seven-item scale where participants rank their feelings about statements on a scale from one (strongly disagree) to six (strongly agree). Statements on the scale include "I feel that people get what they are entitled to have" and "I feel that the world is a fair place" (Lipkus 1991). Reliabilities for GBJW range from 0.79 to 0.82 (Lipkus 1991).

The Big Five Inventory (BFI) was used to assess participants' extraversion, agreeableness, conscientiousness, neuroticism, and openness to new experiences (John et al. 2008). It consists of 44 trait self-descriptors, such as "talkative", "does a thorough job", and "is a reliable worker". For our purposes, participants indicated the extent to which they agreed or disagreed with each statement on a scale from zero to five. Reliabilities for the BFI range from 0.79 to 0.87 (John et al. 2008).

Measures of stereotypes towards social groups. The study employed two separate measures of stereotypes. One measure was the Modern Sexism Scale, which consists of eight statements that assess participants' level of sexism (Swim et al. 1995). Participants used a scale of zero (strongly disagree) to five (strongly agree). Examples of statements are "discrimination against women is no longer a problem in the U.S." and "women often miss out on good jobs due to sex discrimination" (reverse scored) (Swim et al. 1995). Reliabilities for the modern sexism score range from 0.75 to 0.84 (Swim et al. 1995).

A second measure of stereotypes involved asking participants about their feelings about 15 social groups (African Americans, Asians, atheists, Catholics, Caucasians, Democrats, female homosexuals, fundamentalist Christians, Hispanics, Jews, male homosexuals, men, Muslims, Republicans, and women). This study endeavored to use a variety of social groups representing individuals from different political, gender, racial, religious, and sexual orientation groups. Furthermore, this study included social groups that may be viewed positively or negatively by liberals and conservatives. Participants were asked to rate their feelings about each group from 0 (very cold and negative) to 100 (very warm and positive).

Demographic questions. Participants answered demographic questions about their gender, race, ethnicity, age, political identification, and religious affiliation. For the non-US reader, it should be noted that the U.S. is mostly a two-party country, with Democrats being more liberal and Republicans more conservative. University students tend to be more liberal than the general population.

\subsection{Procedure}

Participants were informed that their responses would be anonymous. They filled out a hard copy of the informed consent form prior to beginning the survey on computers, ensuring that they believed assurances about anonymity, as there was no way to link their identity to their responses. Each participant completed the Qualtrics survey on a computer in a group setting. The survey took about 35 minutes to complete. Students were allowed to discontinue their participation at any time. After completing the survey, participants were thanked and awarded class credit.

\section{Results}

To facilitate presentation of the results, some statistical information (such as degrees of freedom or F-values) are not included in the paper, but are available upon request.

\subsection{Political Affiliation}

The two most common political identifications were Democrat (33\%) or no political affiliation (33\%), followed by Republican (18.3\%), Other (7.8\%), Libertarian (6.1\%), and Green party $(1.7 \%)$. To determine if there was a gender gap in political affiliation, a chi-square analysis by gender and the three most prevalent party choices (Democrat, no party affiliation, Republican) was conducted. This analysis was not significant. Women compared to men were equally likely to identify as Democrat (37.9\% vs. $41 \%)$, Republican (22.4\% vs. $20.5 \%)$, or to have no party affiliation (39.7\% and $38.5 \%)$. 


\subsection{Intercorrelations among Conservatism, Religiosity, GBJW, SDO, and the Big Five}

See Table 1 for correlations among conservatism, religiosity, GBJW, SDO, and the Big Five. Self-identified conservatism (the one-item Likert scale item) was correlated with both social and economic conservatism, religiosity, GBJW, SDO, and neuroticism. Social conservatism was correlated with economic conservatism, religiosity, GBJW, and SDO. Economic conservatism was correlated with religiosity and extraversion. Religiosity was correlated with SDO. GBJW was correlated with SDO and conscientiousness. All Big Five dimensions were highly intercorrelated.

\subsection{Interrelations among Measures of Stereotypes: Modern Sexism and Feelings about Social Groups}

Individuals were asked about their feelings about 15 social groups (African Americans, Asians, atheists, Catholics, Caucasians, Democrats, female homosexuals, fundamentalist Christians, Hispanics, Jews, male homosexuals, men, Muslims, Republicans, and women). As Table 2 shows, feelings for 14 of the 15 groups were significantly intercorrelated, indicating that participants who rated one social group positively tended to rate the other social groups positively as well. The only exception was for participants' feelings about Republicans, which did not correlate with feelings about African Americans, Democrats, female or male homosexuals, or women.

Participants who scored high on modern sexism tended to have more negative feelings about Democrats, Hispanics, female and male homosexuals, and women, but rated Republicans more favorably.

\subsection{Interrelations among Conservatism, Religiosity, GBJW, SDO, Big Five, and Measures of Stereotypes}

See Table 3 for correlations among conservatism, religiosity, GBJW, SDO, Big Five, and the two measures of stereotypes (modern sexism and feelings about social groups).

Self-identified conservatism. Participants high in self-identified conservatism compared to those who self-identified as more liberal scored much higher on modern sexism. They also had more negative feelings for African Americans, atheists, Democrats, female and male homosexuals, Hispanics, and Muslims, but felt more positively about Republicans.

Social conservatism. Participants who scored high on social conservatism scored higher on modern sexism. They also had more negative feelings for atheists, Democrats, and female and male homosexuals. Conversely, participants who scored high on social conservatism rated Catholics, Caucasians, fundamentalist Christians, and Republicans more favorably than did participants low in social conservatism.

Economic conservatism. Participants who scored high rather than low on economic conservatism had more negative feelings about atheists and female and male homosexuals. Conversely, participants who scored high on economic conservatism felt more positively about Catholics, fundamentalist Christians, and men.

Religiosity. Participants high in religiosity were higher in modern sexism and had less favorable feelings for atheists, Democrats, and female and male homosexuals.

GBJW. Those high in GBJW had much higher modern sexism scores. Participants who scored high on the GBJW scale also felt more negatively about African Americans, Democrats, female and male homosexuals, Hispanics, Muslims, and women, but rated Republicans more favorably.

Social Dominance Orientation (SDO). Individuals high in SDO scored higher on modern sexism. SDO correlated negatively with feelings about African Americans, Asians, atheists, Democrats, female and male homosexuals, Hispanics, Jews, Muslims, and women.

Big Five. Modern sexism was correlated with conscientiousness. Agreeableness correlated with feelings about Asians, Caucasians, men, and women. Conscientiousness correlated with feelings about men and women. Neuroticism correlated with feelings about Jews and Muslims. 
Table 1. Correlations among modern sexism, conservatism, religiosity, Global Belief in a Just World (GBJW), social dominance orientation (SDO), and the Big Five

\begin{tabular}{|c|c|c|c|c|c|c|c|c|c|c|c|}
\hline Self-Identified Con. & $0.45^{* * *}$ & & & & & & & & & & \\
\hline Social Conservatism & $0.38^{* * *}$ & $0.63^{* * *}$ & & & & & & & & & \\
\hline Economic Conserv. & 0.09 & 0.31 ** & $0.64^{* * *}$ & & & & & & & & \\
\hline Religiosity & $0.24 *$ & $0.32 * *$ & $0.41^{* * *}$ & $0.41^{* * *}$ & & & & & & & \\
\hline GBJW & $0.45^{* * *}$ & $0.46^{* * *}$ & $0.31^{* *}$ & 0.08 & 0.04 & & & & & & \\
\hline $\mathrm{SDO}$ & $0.28 * *$ & $0.43^{* * *}$ & $0.25^{* *}$ & 0.04 & $0.20 *$ & $0.49^{* * *}$ & & & & & \\
\hline Agreeableness & -0.03 & 0.03 & -0.01 & -0.01 & -0.04 & 0.02 & -0.05 & & & & \\
\hline Conscientiousness & 0.20 * & 0.15 & 0.15 & 0.13 & 0.02 & $0.34^{* * *}$ & 0.03 & $0.39 * * *$ & & & \\
\hline Extroversion & 0.04 & 0.17 & 0.16 & $0.22 *$ & 0.10 & 0.07 & 0.01 & $0.38^{* * *}$ & $0.36^{* * *}$ & & \\
\hline Neuroticism & -0.09 & $-0.26 * *$ & -0.12 & 0.13 & 0.04 & 0.00 & -0.06 & $0.43^{* * *}$ & 0.21 * & $0.26 * *$ & \\
\hline \multirow{2}{*}{ Openness New Ex. } & 0.07 & 0.03 & 0.13 & 0.12 & 0.10 & 0.04 & 0.00 & $0.35^{* * *}$ & $0.20 *$ & $0.49 * * *$ & $0.50^{* * *}$ \\
\hline & $\begin{array}{l}\text { Modern } \\
\text { Sexism }\end{array}$ & $\begin{array}{l}\text { Selfidentified } \\
\text { Conservatism }\end{array}$ & $\begin{array}{c}\text { Social } \\
\text { Conservatism }\end{array}$ & $\begin{array}{c}\text { Economic } \\
\text { Conservatism }\end{array}$ & Religiosity & GBJW & $\mathrm{SDO}$ & Agreeableness & Conscientiousness & Extroversion & Neuroticism \\
\hline
\end{tabular}

Table 2. Correlations among the stereotype measures, feelings about social groups and modern sexism.

\begin{tabular}{|c|c|c|c|c|c|c|c|c|c|c|c|c|c|c|c|}
\hline Asians & $0.80^{* * *}$ & & & & & & & & & & & & & & \\
\hline Atheists & $0.50^{* * *}$ & $0.53^{* * *}$ & & & & & & & & & & & & & \\
\hline Catholics & $0.44^{* * *}$ & $0.66^{* * *}$ & $0.29 * *$ & & & & & & & & & & & & \\
\hline Caucasians & $0.51 * * *$ & $0.66^{* * *}$ & $0.40^{* * *}$ & $0.56^{* * *}$ & & & & & & & & & & & \\
\hline Democrats & $0.51^{* * *}$ & $0.39 * * *$ & $0.49 * * *$ & $0.26^{* *}$ & 0.22 * & & & & & & & & & & \\
\hline Lesbians & $0.53 * * *$ & $0.57^{* * *}$ & $0.67^{* * *}$ & 0.22 * & $0.33 * * *$ & $0.59^{* * *}$ & & & & & & & & & \\
\hline $\begin{array}{l}\text { Fundamentalist } \\
\text { Christians }\end{array}$ & $0.41^{* * *}$ & $0.49 * * *$ & 0.22 * & $0.67^{* * *}$ & $0.46^{* * *}$ & 0.23 * & $0.25 * *$ & & & & & & & & \\
\hline Hispanics & $0.78^{* * *}$ & $0.79^{* * *}$ & $0.54^{* * *}$ & $0.57^{* * *}$ & $0.66^{* * *}$ & $0.50^{* * *}$ & $0.57 * * *$ & $0.47 * * *$ & & & & & & & \\
\hline Jews & $0.67^{* * *}$ & $0.78^{* * *}$ & $0.52 * * *$ & $0.58 * * *$ & $0.69 * * *$ & $0.46 * * *$ & $0.55 * * *$ & $0.50 * * *$ & $0.78 * * *$ & & & & & & \\
\hline Male homosexuals & $0.58^{* * *}$ & $0.51 * * *$ & $0.68^{* * *}$ & $0.22 *$ & $0.33^{* * *}$ & $0.62 * * *$ & $0.89 * * *$ & $0.26 * *$ & $0.59 * * *$ & $0.58^{* * *}$ & & & & & \\
\hline Men & $0.56^{* * *}$ & $0.58^{* * *}$ & $0.23 *$ & $0.42 * * *$ & $0.67^{* * *}$ & 0.31 ** & $0.33^{* * *}$ & $0.45 * * *$ & $0.64 * * *$ & $0.59 * * *$ & $0.31^{* *}$ & & & & \\
\hline Muslims & $0.72^{* * *}$ & $0.74^{* * *}$ & $0.55 * * *$ & $0.50^{* * *}$ & $0.47^{* * *}$ & $0.55^{* * *}$ & $0.66^{* * *}$ & $0.43^{* * *}$ & $0.75 * * *$ & $0.80^{* * *}$ & $0.70^{* * *}$ & $0.55^{* * *}$ & & & \\
\hline Republicans & 0.17 & $0.35^{* * *}$ & $0.20 *$ & $0.56^{* * *}$ & $0.59 * * *$ & -0.08 & 0.08 & $0.60^{* * *}$ & $0.30 * * *$ & $0.37^{* * *}$ & 0.07 & $0.47^{* * *}$ & 0.24 * & & \\
\hline & $0.71 * * *$ & $0.66^{* * *}$ & $0.33^{* * *}$ & $0.34^{* * *}$ & $0.46^{* * *}$ & $0.40^{* * *}$ & $0.49 * * *$ & $0.34 * * *$ & $0.66 * * *$ & $0.66^{* * *}$ & $0.46 * * *$ & $0.64^{* * *}$ & $0.67^{* * *}$ & 0.13 & \\
\hline \multirow{2}{*}{ Modern Sexism } & -0.15 & -0.04 & -0.07 & 0.10 & 0.16 & $-0.22 *$ & $-0.22 *$ & 0.03 & -0.04 & -0.11 & $-0.27 * *$ & 0.08 & -0.16 & $0.29 * *$ & -0.23 * \\
\hline & $\begin{array}{c}\text { African } \\
\text { Americans }\end{array}$ & Asians & Atheists & Catholics & Caucasians & Democrats & $\begin{array}{c}\text { Female } \\
\text { Homosexuals }\end{array}$ & $\begin{array}{l}\text { Fundamentalist } \\
\text { Christians }\end{array}$ & Hispanics & Jews & $\begin{array}{c}\text { Male } \\
\text { Homosexuals }\end{array}$ & Men & Muslims & Republicans & Women \\
\hline
\end{tabular}


Table 3. Correlations among the stereotype measures, conservatism, religiosity, GBJW, SDO, and the Big Five

\begin{tabular}{|c|c|c|c|c|c|c|c|c|c|c|c|c|c|c|c|}
\hline Modern Sexism & -0.15 & -0.04 & -0.07 & 0.10 & 0.16 & -0.22 * & $-0.22 *$ & 0.03 & -0.04 & -0.11 & $-0.27 * *$ & 0.08 & -0.16 & $0.29^{* *}$ & $-0.23 *$ \\
\hline $\begin{array}{l}\text { Self-identified } \\
\text { Conservatism }\end{array}$ & $-0.22 *$ & -0.14 & $-0.33 * * *$ & 0.12 & 0.11 & $-0.59 * * *$ & $-0.44^{* * *}$ & 0.17 & -0.22 * & -0.17 & $-0.47^{* * *}$ & 0.11 & $-0.28 * *$ & $0.45 * * *$ & -0.17 \\
\hline Social Conservatism & -0.05 & 0.04 & -0.30 ** & $0.35 * * *$ & $0.18 *$ & $-0.38 * * *$ & $-0.41 * * *$ & 0.27 ** & 0.04 & 0.00 & $-0.40 * * *$ & 0.15 & -0.10 & $0.43 * * *$ & -0.03 \\
\hline Economic Conserv. & 0.06 & 0.08 & $-0.31 * *$ & $0.27 * *$ & 0.04 & -0.04 & $-0.28 * *$ & $0.21 *$ & 0.03 & 0.13 & $-0.24 *$ & $0.22 *$ & 0.14 & 0.14 & 0.13 \\
\hline Religiosity & -0.07 & -0.01 & $-0.39 * * *$ & 0.08 & -0.05 & $-0.23 *$ & $-0.41 * * *$ & 0.12 & 0.14 & -0.02 & $-0.38 * * *$ & 0.08 & -0.11 & 0.11 & -0.09 \\
\hline GBJW & $-0.22 *$ & -0.16 & -0.16 & 0.02 & 0.11 & $-0.35 * * *$ & 0.11 & $-0.28 * *$ & -0.20 * & -0.16 & $-0.23 *$ & 0.00 & $-0.24 * *$ & 0.30 ** & $-0.27 * *$ \\
\hline SDO & -0.36 *** & $-0.31^{* *}$ & $-0.35 * * *$ & -0.06 & -0.10 & $-0.42 * * *$ & $-0.47 * * *$ & -0.10 & $-0.32 * *$ & -0.32 ** & $-0.43 * * *$ & -0.10 & $-0.38 * * *$ & 0.10 & -0.26 ** \\
\hline Agreeableness & 0.13 & $0.22 *$ & 0.08 & 0.14 & 0.22 * & -0.03 & 0.08 & 0.08 & 0.05 & 0.18 & 0.00 & 0.24 * & 0.15 & 0.13 & $0.20 *$ \\
\hline Conscientious-ness & 0.08 & 0.15 & 0.07 & 0.08 & 0.12 & 0.00 & 0.06 & 0.05 & 0.01 & 0.13 & -0.02 & 0.21 * & 0.09 & 0.09 & 0.21 * \\
\hline Extroversion & 0.10 & 0.04 & -0.06 & 0.06 & -0.07 & 0.01 & -0.03 & 0.07 & -0.05 & 0.06 & -0.04 & 0.07 & 0.11 & 0.02 & 0.18 \\
\hline Neuroticism & 0.04 & 0.17 & 0.05 & 0.10 & 0.03 & 0.12 & 0.14 & 0.08 & 0.05 & $0.21 *$ & 0.14 & 0.01 & 0.19 * & -0.13 & 0.04 \\
\hline \multirow{2}{*}{$\begin{array}{l}\text { Openness to New } \\
\text { Experien. }\end{array}$} & 0.00 & 0.13 & 0.04 & 0.13 & 0.09 & 0.03 & 0.07 & 0.14 & -0.05 & 0.16 & 0.02 & -0.02 & 0.10 & 0.10 & 0.04 \\
\hline & $\begin{array}{c}\text { African } \\
\text { Americans }\end{array}$ & Asians & Atheists & Catholics & Caucasians & Democrats & $\begin{array}{c}\text { Female } \\
\text { Homosexuals }\end{array}$ & $\begin{array}{l}\text { Fundamentalist } \\
\text { Christians }\end{array}$ & Hispanics & Jews & $\begin{array}{c}\text { Male } \\
\text { Homosexuals }\end{array}$ & Men & Muslims & Republicans & Women \\
\hline
\end{tabular}




\subsection{Absolute Positivity and Negativity of Feelings about Social Groups}

Correlations only show the direction of the relation between two variables, but cannot elucidate if feelings about social groups are positive or negative at an absolute level. To get closer to the question of whether conservatives or liberals have more positive or negative feelings about the social groups tested, ANOVAs were conducted by comparing individuals who identified as either Democrats (38) or Republicans (21), excluding other participants from this set of analyses.

Table 4 reveals that there are a few consistencies in how Democrats and Republicans rated the 15 social groups. They both rated women and Asians highly positively and members of the other political party and atheists most negatively. Aside from this overlap, Democrats rated the following groups significantly more positively than Republicans did: atheists, Democrats, female and male homosexuals, and Muslims. The social groups that Republicans rated significantly more positively than Democrats did were Catholics, Caucasians, and Republicans.

Table 4. Mean Ratings of Liking for 15 Social Groups.

\begin{tabular}{cccc}
\hline Social Group & Entire Sample & Democrats & Republicans \\
\hline Women & 82.2 & 83.7 & 83.4 \\
Hispanics & 75.0 & 78.3 & 74.7 \\
Asians & 74.6 & 74.7 & 78.2 \\
Men & 73.7 & 74.0 & 83.0 \\
African Americans & 73.1 & 77.6 & 72.0 \\
Caucasians & 70.9 & $66.3^{* *}$ & 84.3 \\
Jews & 70.5 & 69.9 & 71.6 \\
Catholics & 66.9 & $65.6^{*}$ & 79.6 \\
Muslims & 66.3 & $70.9^{*}$ & 58.7 \\
Female homosexuals & 63.5 & $71.6^{* *}$ & 45.9 \\
Fundamentalist Christians & 62.3 & 62.4 & 73.5 \\
Male homosexuals & 61.3 & $71.8^{* * *}$ & 41.8 \\
Democrats & 59.6 & $76.1^{* * *}$ & 33.2 \\
Republicans & 55.9 & $47.1^{* * *}$ & 81.6 \\
Atheists & 55.7 & $62.1^{*}$ & 43.3 \\
\hline
\end{tabular}

Notes. Ratings can range from $0-100$, with 100 being the most favorable. Denotes significant differences between Democrats and Republicans: ${ }^{*} p<0.05 ;{ }^{* *} p<0.01 ;{ }^{* * *} p<0.000$.

Republicans scored significantly higher than Democrats on modern sexism, self-identified conservatism, social conservatism, SDO, GBJW, and religiosity.

\section{Discussion}

\subsection{Intercorrelations among Conservatism, Religiosity, GBJW, SDO, and the Big Five}

The three measures of conservatism (self-identified, social, and economic conservatism) were intercorrelated, and all three also correlated with religiosity. Both self-identified conservatism and social conservatism, but not economic conservatism, were also correlated with GBJW, and SDO. Economic conservatism thus appears to tap into a somewhat different aspect of conservatism. This constellation of positive correlations among self-identified and social conservatism on the one hand, and religiosity, GBJW, and SDO on the other hand, reveals that conservatives tend to be more religious, more likely to believe that bad things happen to bad people, and more likely to believe in the importance of dominance and inequality, than liberals. Dittmar and Dickinson (1993) also found a correlation between GBJW and political conservatism.

Interestingly, this study did not replicate the relation between political conservatism and conscientiousness found by Carney et al. (2008), openness to new experiences (DeYoung et al. 2007), or lower agreeableness (Hirsh et al. 2010). Instead, conservatives scored lower on neuroticism than 
liberals did. Thus, the findings for the relation between the Big Five personality dimensions and political attitudes were inconclusive.

\subsection{Interrelations among Measures of Stereotypes: Modern Sexism and Feelings about Social Groups}

Feelings about social groups. Individuals' feelings for 14 out of the 15 social groups were significantly intercorrelated. In other words, participants who rated one social group positively tended to rate the other social groups positively as well, which replicates findings by Chambers et al. (2013); see Table 2 . The one exception was for people with highly positive feelings for Republicans, who did not have positive or negative feelings for African Americans, Democrats, female or male homosexuals, or women. Given the highly positive relations among feelings for all other social groups, this lack of a positive correlation between feelings for Republicans, on the one hand, and African Americans, Democrats, female and male homosexuals, and women, on the other hand, is noteworthy, a point which will be examined in more detail below. Furthermore, positive feelings for Republicans were correlated with modern sexism.

Participants high in modern sexism had more negative feelings for 5 of the 15 social groups-Democrats, Hispanics, female and male homosexuals, and women-but rated Republicans more favorably. Thus, modern sexism, despite its name, appears to relate not only to negative stereotypes about women, but rather extends to several other social groups as well. It is possible that holding strong negative stereotypes about one social group increases the likelihood that one holds negative stereotypes of other groups as well. In fact, prejudice towards different social groups tends to be highly intercorrelated, at least for explicit measures (Bergh et al. 2012). Individuals who score high in sexism typically deny that women are on the receiving end of discrimination. This lack of awareness of gender discrimination actually contributes to gender discrimination (Begeny et al. 2020). Thus, if individuals high in modern sexism hold negative stereotypes against social groups besides women, this has troubling implications for social justice and economic opportunities for racial, ethnic, religious, and sexual orientation minorities.

\subsection{Conservatism and Stereotypes}

Self-identified conservatism was among the variables most closely related to negative feelings about social groups (see Table 3). Participants high in self-identified conservatism had less positive feelings about racial, religious, and sexual minorities and about those with opposing political viewpoints (such as atheists and Democrats) than self-identified liberals did. Participants high in self-identified conservatism showed less favorable feelings about individuals who are often on the receiving end of discrimination such as African Americans, Hispanics, female and male homosexuals, and Muslims, while feeling more positively about Republicans. Furthermore, self-identified conservatism correlated with modern sexism.

Individuals high in social conservatism were similar to individuals high in self-identified conservatism in their negative feelings about atheists, Democrats, and female and male homosexuals, but did not show more negative feelings about African Americans and Muslims. Individuals high in social conservatism were similar to individuals high in self-identified conservatism in their positive feelings about Republicans, but they also held more positive feelings about Catholics, Caucasians, and fundamentalist Christians. These feelings may be due to both liberals and conservatives liking individuals more when they assume that members of social groups have politically similar, and less if they have politically opposite attitudes (Mallinas et al. 2018). Social conservatism was also correlated with modern sexism.

Those high in economic conservatism held more negative feelings about atheists, female and male homosexuals, and positive feelings about Catholics, fundamentalist Christians, and men. Interestingly, unlike self-identified and social conservatism, economic conservatism was not correlated with modern sexism. 
In summary, the social groups that were viewed negatively when assessed using any of the three operationalizations of conservatism (self-identified, social, or economic) were atheists and female and male homosexuals. Overall, those high in self-identified conservatism held more negative feelings about seven social groups, while those high in social conservatism about five groups. Of the three measures of conservatism, economic conservatism showed the lowest level of negative feelings towards three groups, and this was the only measure of conservatism that did not correlate with modern sexism. This does indicate that despite the fact that the three operationalizations of conservatism are interrelated, they do tap into distinct types of conservatism, with self-identified conservatism relating to the most negative feelings about social groups.

It bears pointing out that liberals also harbored negative feelings about certain social groups. Those who scored low on self-identified conservatism and hence were more liberal had more negative views of Republicans. Those low in social conservatism had more negative feelings for Catholics, Caucasians, fundamentalist Christians, and Republicans, and those low in economic conservatism had more negative feelings about Catholics, fundamentalist Christians, and men. Thus, liberals did hold more negative feelings about certain social groups than conservatives did. However, overall, liberal individuals showed less negative feelings about social groups than conservatives did. This does suggest that both conservatives and liberals hold negative stereotypes, but that the social groups associated with those stereotypes differ. Not surprisingly, negative feelings are strong against those who have opposing viewpoints; both conservatives and liberals reserved their most negative feelings for their political opponents i.e., Democrats and Republicans, respectively.

However, beyond that, conservatives held more negative feelings about racial, religious, and sexual minorities and more positive feelings about the "White majority", e.g., Caucasians and Christians, than liberals did. A similar result was also obtained by Chambers et al. (2013) and interpreted as evidence that liberals are just as prejudiced as conservatives. This interpretation is not entirely justified. While it is clear that liberals are not immune to negative stereotypes, the effect of negative stereotypes held against disadvantaged versus advantaged groups is far from equivalent. Liberals' negative stereotypes of those in power, such as Caucasians and Christians (groups to which many liberals actually belong) are unlikely to have the same detrimental effects on those advantaged groups as conservatives' negative stereotypes of groups that have been disadvantaged or discriminated against, such as racial and religious minorities and members of the LGBTQ community. The latter groups are the ones that still suffer from employment, housing, and other forms of discrimination and are more frequently targets of hate crimes (e.g., see the Federal Bureau of Investigation's [FBI] Uniform Crime Reports' most recent data). According to Jost et al. (2018, p. 58) "liberals and leftists are motivated by (humanistic) concerns for equality (and social justice), and this leads them to embrace social change, whereas conservatives and rightists are motivated by the (normative) desire to preserve tradition (and social order), and this is what leads them to defend and justify inequalities in the social system." Similarly, Graham et al. (2009) found that liberals valued harm/care and fairness/reciprocity more than conservatives did, whereas conservatives valued all five foundations (harm/care, fairness/reciprocity, ingroup/loyalty, authority/respect, and purity/sanctity) equally, revealing a difference in the value systems of conservatives and liberals.

It must be noted that the greater negativity of conservatives to social groups could be a function of the particular social groups included in this survey. This problem does not apply to the second measure of stereotyping, modern sexism. Individuals high in self-identified or social conservatism scored higher in modern sexism. Overall, this provides some evidence for greater stereotyping among conservatives than liberals.

\subsection{Religiosity and Stereotypes}

Participants high in religiosity indicated less favorable feelings about atheists, Democrats, and female and male homosexuals. Furthermore, religiosity was correlated with modern sexism. The distinguishing feature for highly religious compared to highly conservative individuals was 
that while both demonstrated negative feelings about sexual minorities and those with opposing viewpoints (atheists and Democrats), highly religious individuals did not have negative feelings for racial minorities or Muslims. This is in contrast to Hodson and Dhont's (2015) results that individuals high in religiosity held homophobic AND racist views. Like conservatives, highly religious individuals are generally resistant to change, which predicts negative attitudes toward sexual minorities (Van der Toorn et al. 2017). Jones (2010) reports that religiosity correlates with opposition to same-sex marriage.

\subsection{GBJW and Stereotypes}

A high score on GBJW means that one believes that people tend to get the rewards and punishments they deserve. GBJW related to stereotypes in several ways. First, it was very strongly correlated with modern sexism. Furthermore, participants high in GBJW rated African Americans, Democrats, Hispanics, female and male homosexuals, Muslims, and women less favorably, but rated Republicans more favorably. Individuals high in GBJW were very similar in their feelings about social groups as self-identified conservatives, with the exception of a lack of more negative feelings about atheists, but instead more negative feelings about women. This is consistent with previous research, as political conservatism is known to correlate with GBJW (Dittmar and Dickinson 1993). In summary, high GBJW related to more negative feelings about seven of the 15 social groups and more positive feelings for one group. GBJW also correlates with belief in racial wealth equality and the perception that inequality is due to personal traits, such as laziness (Kraus et al. 2019). Hence future research should further examine the role of GBJW in negative stereotypes.

\subsection{Social Dominance Orientation (SDO)}

SDO, which refers to valuing power and dominance, correlated with modern sexism. It also was related to more negative feelings about ten of the 15 social groups: African Americans, Asians, atheists, Democrats, female and male homosexuals, Hispanics, Jews, Muslims, and women. In fact, SDO emerged as the variable most closely related to negative feelings about social groups that have been subject to discrimination: racial, gender, sexual, and religious minorities. The negative orientation towards Asians is noteworthy given that no other measure yielded a negative correlation with feelings about Asians. (Note that this study predates the COVID-19 pandemic and the associated increased negative stereotypes about Chinese and other Asian individuals.)

Thus, individuals high in SDO seemed to hold more negative views of many social groups, although they disliked some groups more than others. This suggests a certain disagreeable disposition, and yet, SDO was not correlated with agreeableness. A previous meta-analysis had found a negative correlation between SDO and agreeableness (Sibley and Duckitt 2008). Persons high in SDO have been found to dislike social groups that are either low in power or compete with them (Duckitt 2001, 2015; Duckitt and Sibley 2009; Sibley and Duckitt 2008). They are also more inclined towards aggression, intergroup hostility, and political violence (Bartusevičius et al. 2020). A meta-analysis by Sibley and Duckitt (2008) also found that SDO predicts prejudice. Thus, SDO appears to be an even stronger predictor of negative stereotypes than political conservatism is.

\subsection{Big Five and Stereotypes}

There were only a few significant correlations between the Big Five dimensions and feelings about social groups. There were positive correlations between agreeableness on the one hand and feelings about Asians, Caucasians, men, and women on the other hand. Neuroticism was positively correlated with feelings about Jews and Muslims. High levels of conscientiousness were positively correlated with feelings about men and women, and it also correlated with modern sexism. The hypothesis that measures of stereotyping would negatively correlate with agreeableness was not confirmed. These results do not show a consistent pattern and do not replicate research on the relation between low agreeableness and negative stereotypes (Brandt and Crawford 2019; 
Crawford and Brandt 2019; Sibley and Duckitt 2008) and low openness to new experiences and negative stereotypes (Sibley and Duckitt 2008).

\subsection{Democrats, Republicans, and Stereotypes}

To address the absolute level of negative or positive feelings about social groups, conservatives and liberals were dichotomized into two groups based on their identification as Republican or Democrat. Individuals who did not identify with either of the two major parties were not included in this analysis. Note that this invariably reduces sample size and thereby statistical power.

As Table 4 illustrates, Democrats and Republicans rated women and Asians very positively and atheists and particularly members of the other political party most negatively, revealing the huge chasm between the two political groups. Aside from this overlap, Democrats rated atheists, Democrats, female and male homosexuals, and Muslims significantly more positively than Republicans did. The social groups Republicans rated significantly more positively than Democrats did were Catholics, Caucasians, and Republicans. Thus, Democrats rated groups that have traditionally been subjected to racial, religious, or sexual discrimination more positively than Republicans did. Overall, Democrats rated five social groups more positively than Republicans did, while Republicans rated three groups more positively than Democrats did.

In terms of outcomes for society, what is more important than the absolute number of social groups for whom one holds negative stereotypes, is the type of social groups against which stereotypes are held. Democrats rated groups that have traditionally been subjected to racial, religious, or sexual discrimination and disenfranchisement more positively than Republicans did, while Republicans favored groups that are associated with the "White majority". This replicates our findings for conservatives versus liberals discussed above.

The other operationalization of stereotypes was modern sexism. This measure provided clear evidence that Republicans scored higher than Democrats. Republicans also scored higher on self-identified conservatism, social conservatism, SDO, GBJW, and religiosity. The picture that emerges from this constellation of interrelations is that of a particular worldview that emphasizes the status quo and views those who challenge it, such as racial or religious minorities or those outside of the heterosexual norm, with suspicion.

It is noteworthy that the most consistently negative feelings against the social groups were towards atheists and female and male homosexuals (see Table 2). Attitudes towards homosexuality have undergone a recent monumental shift (e.g., Charlesworth and Banaji 2019). However, while in the US support for issues such as same-sex marriages had risen to $70 \%$ in 2020 , clearly many negative attitudes remain, especially among Republicans, a group where only about half support same-sex marriage (PRRI Staff 2020, 19 October 2020). Prusaczyk and Hodson (2020) found that individuals high in conservatism showed more prejudice toward gender non-conformists, a pattern replicated in this study. According to Hodson and Dhont (2015), homosexuals and gender non-conformists are perceived as threatening the status quo of traditional marriage and parenthood. Indeed, individuals outside the heterosexual, cisgender norm tended to be among the most disliked social groups of conservatives and Republicans (see Table 4).

Thus, the hypothesis that conservatives hold more negative stereotypes than liberals received support. However, Democrats did have more negative feelings about Catholics, Caucasians, and Republicans than Republicans did. Thus, they are not immune to stereotyping. However, it is noteworthy that Democrats had more positive feelings for disenfranchised groups than Republicans did and also scored lower in modern sexism.

\subsection{Limitations of This Research and Directions for the Future}

One limitation of this research is the small sample size inherent in conducting research at smaller institutions. Furthermore, the research was conducted at one small, public university in the Midwest of the US. Hence generalizability may be limited. Critics may also find fault with the particular social 
groups selected as targets in this research. However, several of the groups were specifically selected because they represent groups that have traditionally been the targets of discrimination and hate crimes. Understanding who may hold negative stereotypes against such groups is important.

With 20/20 hindsight, the original hypothesis that conservatives show more negative stereotypes than liberals seems simplistic. Clearly, this research has found that liberals also display negative stereotypes, e.g., against Republicans and Caucasians. In terms of relevance for our troubled times where negative stereotypes and hate crimes have seen a resurgence (Federal Bureau of Investigation 2020), what may be more important than whether a particular group is more biased than another, is what the consequences of such negative stereotypes are for various social groups. What are the consequences of holding negative stereotypes of advantaged versus disadvantaged social groups? And exactly why do conservatives and liberals differ in the social groups about whom they feel negatively? And how do SDO, GBJW, religiosity, and other individual difference variables affect negative stereotypes? These are questions that require further study.

\section{Conclusions}

This research found that individuals with strong political convictions appear to be biased against those with opposing viewpoints. In fact, some of the strongest negative stereotypes were held by members of the two major US political parties about members of the other political party. While there was evidence that we tend to dislike those whose views conflict with our own, the picture that emerges from this study is that conservatism, SDO, and GBJW often go along with stereotypical views of others (such as modern sexism) and negative feelings about groups that have been stigmatized (such as racial or religious minorities and individuals outside of the heterosexual norm). Thus, it does not appear to be a case of one group being biased and another group being devoid of bias; instead, different groups' biases are directed against different types of social groups, some of whom (e.g., certain racial groups or those outside of the heterosexual norm) are more vulnerable to being targets of negative stereotypes and discrimination. To better understand what predicts negative stereotypes against disadvantaged social groups and what we can do to counteract them is a worthwhile endeavor for future research.

Funding: This research received no external funding.

Conflicts of Interest: The author declares no conflict of interest.

\section{References}

Adorno, T. W., Else Frenkel-Brunswik, Daniel J. Levinson, and R. Nevitt Sanford. 1950. The Authoritarian Personality. New York: Harper.

Baron, Jonathan, and John T. Jost. 2019. False equivalence: Are liberals and conservatives in the United States equally biased? Perspectives on Psychological Science 14: 292-303. [CrossRef]

Bartusevičius, Henrikas, Florian van Leeuwen, and Michael B. Petersen. 2020. Dominance-driven autocratic political orientations predict political violence in western, educated, industrialized, rich, and democratic (WEIRD) and non-WEIRD samples. Psychological Science, 1-20. [CrossRef]

Begeny, C. T., M. K. Ryan, C. A. Moss-Racusin, and G. Ravetz. 2020. In some professions, women have become well represented, yet gender bias persists-Perpetuated by those who think it is not happening. Science Advances 6: eaba7814. [CrossRef]

Bergh, Robin, Nazar Akrami, and Bo Ekehammar. 2012. The personality underpinnings of explicit and implicit generalized prejudice. Social Psychological and Personality Science 3: 614-62. [CrossRef]

Brandt, Mark J., and Jarret T. Crawford. 2019. Studying a heterogeneous array of target groups can help us understand prejudice. Current Directions in Psychological Science 28: 292-98. [CrossRef]

Brandt, Mark J., Christine Reyna, John R. Chambers, Jarret T. Crawford, and Geoffrey Wetherell. 2014. The Ideological-Conflict Hypothesis: Intolerance among both liberals and conservatives. Current Directions in Psychological Science 23: 27-34. [CrossRef]

Byrne, Donald. 1971. The Attraction Paradigm. New York: Academic Press. 
Carney, Dana R., John T. Jost, Samuel D. Gosling, and Jeff Potter. 2008. The secret lives of liberals and conservatives: Personality profiles, interaction styles, and the things they leave behind. Political Psychology 29: 807-40. [CrossRef]

Chambers, John R., Barry R. Schlenker, and Brian Collisson. 2013. Ideology and prejudice: The role of value conflicts. Psychological Science 24: 140-49. [CrossRef] [PubMed]

Charlesworth, Tessa E. S., and Mahzarin R. Banaji. 2019. Patterns of implicit and explicit attitudes: I. Long-term change and stability from 2007 to 2016. Psychological Science 30: 174-92. [CrossRef] [PubMed]

Crandall, Christian S., Jason M. Miller, and Mark H. White. 2018. Changing norms following the 2016 U.S. presidential election: The Trump effect on prejudice. Social Psychological and Personality Science, 1-7. [CrossRef]

Crawford, Jarret T., and Mark J. Brandt. 2019. Who is prejudiced, and toward whom? The Big Five traits and generalized prejudice. Personality and Social Psychology Bulletin, 1-13. [CrossRef]

DeYoung, Colin G., Lena C. Quilty, and Jordan B. Peterson. 2007. Between facets and domains: 10 aspects of the Big Five. Journal of Personality and Social Psychology 93: 880-96. [CrossRef]

Dittmar, Helga, and Julie Dickinson. 1993. The perceived relationship between the belief in a just world and sociopolitical ideology. Social Justice Research 6: 257-72. [CrossRef]

Ditto, Peter H., Brittany S. Liu, Cory J. Clark, Sean P. Wojcik, Eric E. Chen, Rebecca H. Grady, Jared B. Celniker, and Joanne F. Zinger. 2018. At least bias is bipartisan: A meta-analytic comparison of partisan bias in liberals and conservatives. Perspectives on Psychological Science 14: 273-91. [CrossRef] [PubMed]

Duckitt, John. 2001. A dual-process cognitive-motivational theory of ideology and prejudice. In Advances in Experimental Social Psychology. Edited by Mark P. Zanna. San Diego: Academic Press, vol. 33, pp. 41-113.

Duckitt, John. 2015. Authoritarian Personality. In International Encyclopedia of the Social E Behavioral Sciences, 2nd ed. Edited by J. D. Wright. Oxford: Elsevier, vol. 2, pp. 255-61.

Duckitt, John, and Chris G. Sibley. 2009. A dual-process motivational model of ideology, politics, and prejudice. Psychological Inquiry 20: 98-109. [CrossRef]

Everett, Jim A. 2013. The 12 Item Social and Economic Conservatism Scale (SECS). PLoS ONE 8: e82131. [CrossRef] [PubMed]

Federal Bureau of Investigation. 2020. 2018 Hate Crime Statistics. Available online: https://ucr.fbi.gov/hate-crime/ 2018/topic-pages/victims (accessed on 17 October 2020).

Graham, Jesse, Jonathan Haidt, and Brian A. Nosek. 2009. Liberals and conservatives rely on different sets of moral foundations. Journal of Personality and Social Psychology 96: 1029-46. [CrossRef] [PubMed]

Hirsh, Jacob B., Colin G. DeYoung, Xiaowen Xu, and Jordan B. Peterson. 2010. Compassionate liberals and polite conservatives: Associations of agreeableness with political ideology and moral values. Personality and Social Psychology Bulletin 36: 655-64. [CrossRef] [PubMed]

Ho, Arnold K., Jim Sidanius, Nour Kteily, Jennifer Sheehy-Skeffington, Felicia Pratto, Kristin E. Henkel, Rob Foels, and Andrew L. Stewart. 2015. The nature of social dominance orientation: Theorizing and measuring preferences for intergroup inequality using the new SDO7 scale. Journal of Personality and Social Psychology 109: 1003-28. [CrossRef] [PubMed]

Hodson, Gordon, and Kristof Dhont. 2015. The person-based nature of prejudice: Individual difference predictors of intergroup negativity. European Review of Social Psychology 26: 1-42. [CrossRef]

John, Oliver P., Laura P. Naumann, and Christopher J. Soto. 2008. Paradigm shift to the integrative Big Five trait taxonomy: History, measurement, and conceptual issues. In Handbook of Personality: Theory and Research. Edited by Oliver P. John, Richard W. Robins and Lawrence A. Pervin. New York: Guilford Press, pp. 114-58.

Jones, Jeffrey M. 2010. Americans' Opposition to Gay Marriage Eases Slightly. Gallup Poll. Available online: http://www.gallup.com/poll/128291/americans-opposition-gay-marriage-eases-slightly.aspx (accessed on 24 May 2010).

Jost, John T., Jaime L. Napier, Hulda Thorisdottir, Samuel D. Gosling, Tibor P. Palfai, and Brian Ostafin. 2007. Are needs to manage uncertainty and threat associated with political conservatism or ideological extremity? Personality and Social Psychology Bulletin 33: 989-1007. [CrossRef]

Jost, John T., Joanna Sterling, and Chadly Stern. 2018. Getting closure on conservatism, or the politics of epistemic and existential motivation. In The Motivation-Cognition Interface. Edited by Catalina E. Kopetz and Ayelet Fishbach. New York: Taylor \& Francis, pp. 56-87.

Kraus, Michael W., Ivuoma N. Onyeador, Natalie M. Daumeyer, Julian M. Rucker, and Jennifer A. Richeson. 2019. The misperception of racial economic inequality. Perspectives on Psychological Science 14: 899-921. [CrossRef] 
Lipkus, Isaac. 1991. The construction and preliminary validation of a Global Belief in a Just World Scale and the exploratory analysis of the Multidimensional Belief in a Just World Scale. Personality and Individual Differences 12: 1171-78. [CrossRef]

Mallinas, Stephanie R., Jarret T. Crawford, and Shana Cole. 2018. Political opposites do not attract: The effects of ideological dissimilarity on impression formation. Journal of Social and Political Psychology 6: 49-75. [CrossRef]

Pratto, Felicia, Jim Sidanius, Lisa M. Stallworth, and Bertram F. Malle. 1994. Social dominance orientation: A personality variable predicting social and political attitudes. Journal of Personality and Social Psychology 67: 741-63. [CrossRef]

PRRI Staff. 2020. Dueling Realities: Amid Multiple Crises, Trump and Biden Supporters See Different Priorities and Futures for the Nation. October 19. Available online: https://www.prri.org/research/amidmultiple-crises-trump-and-biden-supporters-see-different-realities-and-futures-for-the-nation/ (accessed on 10 October 2020).

Prusaczyk, Elvira, and Gordon Hodson. 2020. The roles of political conservatism and binary gender beliefs in predicting prejudices toward gay men and people who are transgender. Sex Roles 82: 438-46. [CrossRef]

Sibley, Chris G., and John Duckitt. 2008. Personality and prejudice: A meta-analysis and theoretical review. Personality and Social Psychology Review 12: 248-79. [CrossRef] [PubMed]

Swim, Janet K., Kathryn J. Aikin, Wayne S. Hall, and Barbara A. Hunter. 1995. Sexism and racism: Old-fashioned and modern prejudices. Journal of Personality and Social Psychology 68: 199-214. [CrossRef]

Tajfel, Henry. 1982. Social psychology of intergroup relations. Annual Review of Psychology 33: 1-39. [CrossRef]

Van der Toorn, Jojanneke, John T. Jost, Dominic J. Packer, Sharareh Noorbaloochi, and Jay J. van Bavel. 2017. In defense of tradition: Religiosity, conservatism, and opposition to same-sex marriage in North America. Personality and Social Psychology Bulletin 43: 1455-68. [CrossRef]

Wetherell, Geoffrey A., Mark J. Brandt, and Christine Reyna. 2013. Discrimination across the ideological divide: The role of value violations and abstract values in discrimination by liberals and conservatives. Social Psychological and Personality Science 4: 658-67. [CrossRef]

Publisher's Note: MDPI stays neutral with regard to jurisdictional claims in published maps and institutional affiliations.

(C) 2020 by the author. Licensee MDPI, Basel, Switzerland. This article is an open access article distributed under the terms and conditions of the Creative Commons Attribution (CC BY) license (http://creativecommons.org/licenses/by/4.0/). 